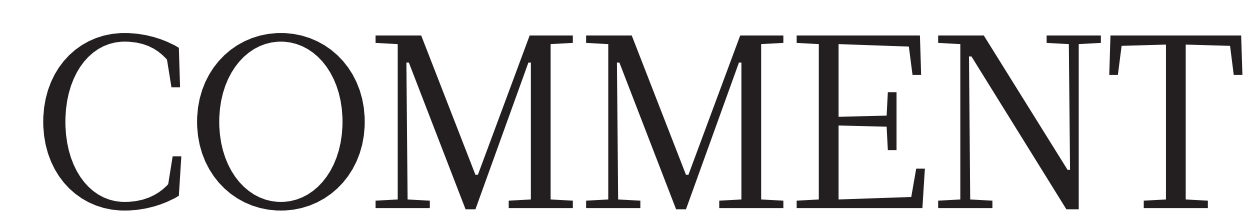

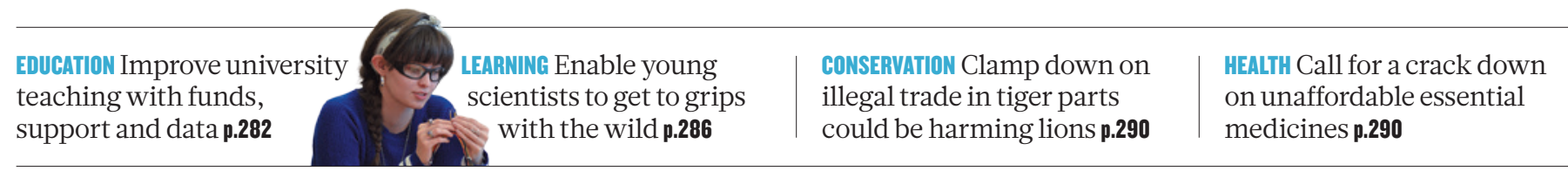

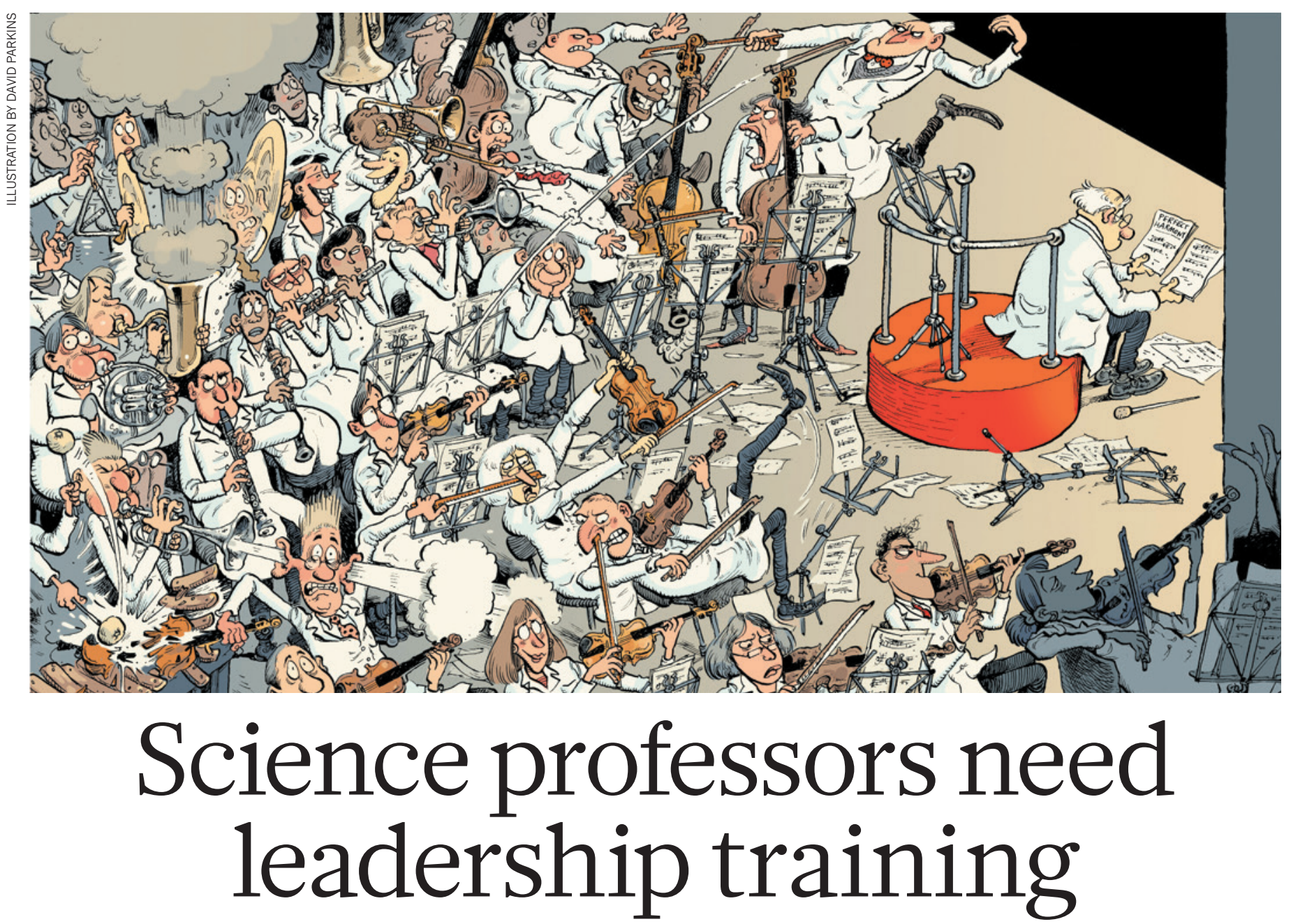

To drive discovery, scientists heading up research teams large and small need to learn how people operate, argue Charles E. Leiserson and Chuck McVinney.

$\mathrm{E}$ ducation does not stop. Professors must update and develop their technical skills throughout their careers. But as they progress, few take the time - or are offered the opportunity - to become educated in how to be an effective leader.

As a consequence, academic teams waste time dealing with unproductive interpersonal issues, lack of motivation and unnecessary conflict. When things do not run smoothly, the costs in terms of money, productivity and retention of talent are high ${ }^{1}$.

Leaders should inspire others to achieve clearly articulated, shared goals. Professors head research teams and manage teaching staff. They lead intellectually, charting directions for advances in engineering and science that benefit society.

And the importance of these leadership skills grows as scientists gain in seniority. Even well-meaning senior professors can wreak havoc by throwing their power around and failing to take into account the

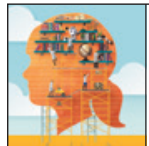

emotions of others or their own. Equally, principal investigators taking too much of a back seat can result in teams being less than the sum of their parts.

Take this true (sanitized) scenario. A major university laboratory wanted to replace their retiring director. There was no doubt as to the successor - the energetic and popular assistant director was a shoo-in. At the first meeting of the search committee, made up of a few senior lab members, the chair reviewed the procedures, which included soliciting opinions from the rest of the faculty. A consensus quickly emerged $>$ 
that this 'bureaucratic process' would be a waste of time. "We know what the answer will be," they said. "Everybody likes him. Let's just appoint him now."

See the committee's blind spot? They were threatening to marginalize the rest of the lab, particularly junior faculty members, by failing to get their buy-in for the appointment. Instead of saving time, this high-handed behaviour could have degraded the collegiality of the lab and required needless effort to deal with the fallout. A professor who feels disenfranchised is less motivated to help solve lab issues, leaving more work for others. If they depart for greener pastures, the rest of the faculty must hire a replacement, cover the lost professor's classes and take responsibility for abandoned graduate students. When emotions are involved, what seems like expediency can turn out to be the opposite.

In this case, one member of the committee did show true leadership, even though she had no official leadership position. She explained the risks of the rash action and persuaded a majority of the committee that the 'bureaucratic process' was a necessary step. The faculty interviews identified major issues for the next lab director to face, and when the popular assistant director was promoted as expected, he had a mandate for instituting important changes.

\section{LEADERSHIP LESSONS}

Over the past dozen years, we have taught leadership workshops for hundreds of engineering and science faculty members. Hardly any of the professors had ever taken a class in leadership skills or knew of any other programme similar to ours. Those who had had leadership education learned it in industry. US corporations spend about US $\$ 14$ billion each year on educating their employees in leadership and management (see go.nature. $\mathrm{com} / 2 \mathrm{kgaya}$ ). But whereas universities welcome business people taking management training courses, leadership - a word synonymous with administration and manipulation - seems to be a dirty word when it comes to their own faculty members.

Being a professor is a human-centred activity. We work with people. We teach students in classrooms, mentor our $\mathrm{PhD}$ students, collaborate with peers and try to persuade people in funding agencies to give us money. But leading people can be difficult, because people are not entirely rational ${ }^{2}$. At most universities, junior faculty members must learn leadership skills on the job by trial and error, to the detriment of their students and careers. Senior faculty members may not understand that a failure to provide a supportive and collegial culture harms the reputation of their department or laboratory, and that they may be ill-equipped to engage effectively in large collaborative projects, such as those that dominate genomics and particle physics.

We call on academic institutions to invest in developing their professors' humancentred leadership skills.

\section{BACK TO SCHOOL}

We met in 1999. One of us (C.E.L.) had taken a two-year leave from Massachusetts Institute of Technology (MIT) in Cambridge during the Internet boom to serve as director of system architecture at the MIT start-up Akamai Technologies. Most of the firm's original 100 engineering staff were recruited directly from MIT and other top universities.

At the start, these brilliant academics were totally dysfunctional as a team. Every interpersonal issue you can imagine

"Research teams are best formed from a mix of diverse thinkers." arose: alienation, anger, apathy, arrogance, belligerence, contempt, despair, disgust, disrespect, envy, exasperation, fear, hate, impatience, indifference, jealousy, outrage, resentment, self-righteousness, spite, suspicion, vindictiveness - the whole gamut. Despite their intellectual prowess, these erstwhile academic colleagues could find no way out of this emotional morass. Many worried that they had made the wrong move in leaving academia. Morale was low.

Fortunately, Akamai's vice-president of human resources, Steve Heinrich, supplied the right medicine. He brought in the other of us (C.M.), an experienced management consultant, to run an intensive leadership workshop for the technical leaders. Topics included dealing with emotions in the workplace; working effectively with people who think differently from you; fostering creativity; resolving conflicts; giving effective feedback; learning to recognize when different situations call for different leadership strategies; and understanding how learning curves relate to motivation. The results were immediate: harsh feelings dissipated, the engineering staff began to cooperate and technical successes started to pile up.

Back at MIT, we wondered why these 'soft' leadership skills were not being taught to engineering and science professors. The same kinds of emotional issues arise in university labs as in corporate workplaces. Although professors pride themselves on their rationality, they have feelings, too.

So, the two of us teamed up to adapt materials normally used for corporate training to the academic context. We also developed university-specific content from scratch, including role-playing activities involving professors and funding agencies, professors and peers, and professors and students.

We offered the workshop for the first time in 2002 to a computer-science lab (C.E.L.'s) at MIT. The response was so positive that we expanded participation to include the
Electrical Engineering and Computer Science department, and eventually, the School of Engineering and the School of Science. In 2007, we offered our two-day workshop to professors outside MIT (see shortprograms.mit.edu/lsf).

Hundreds of professors in the United States and several other countries have now taken our workshop at MIT and through custom offerings at the University of California, Berkeley; Purdue University in West Lafayette, Indiana; Harvard University in Cambridge, Massachusetts; and the National University of Singapore. Participants often express amazement at what a little leadership education can do, from reducing the number of hours spent on interpersonal issues to supplying tools for motivating students.

Our workshop focuses on how people can work together effectively. It promotes selfawareness of personal styles of leadership and offers participants new approaches to explore. Through interactive activities, selfassessment exercises and group discussions, attendees develop a repertoire of strategies for addressing common situations such as how to pitch your research programme to people outside your discipline.

Because leadership styles are individual and situational, we are careful not to judge styles as good or bad, focusing instead on helping participants to see that there may be more options available than they realized. For example, although graduate students sometimes respond well to in-depth coaching from their adviser, there are times when over-involvement can be suffocating, such as when students are starting out and need some space to get their bearings.

Participants practice their skills. For example, the module on conflict resolution concerns a dispute between two students on first authorship. One participant plays the part of the professor trying to resolve the dispute. Method-acting techniques encourage the participants playing the students to empathize with their characters, making the activity as close to a model of a realworld situation as it can be in the classroom, emotions included.

\section{THINKING DIFFERENTLY}

We use the Herrmann Brain Dominance Instrument $(\mathrm{HBDI})^{3}$, a self-assessment survey, to explore participants' mental diversity. Most people think of diversity in terms of the first three things that psychologists say people notice when meeting someone new: race, gender and age. But there is probably more diversity in how people think than in any physical aspect of their being.

Creativity researcher Ned Herrmann originally developed the HBDI in 1979 when he was leading management education at the General Electric conglomerate. 
Herrmann was inspired by neuropsychologist Roger Sperry's work on 'split-brain' patients ${ }^{4}$, which showed that different areas of the brain perform specific functions (Sperry shared the 1981 Nobel Prize in Physiology and Medicine for the work). In most people, the left hemisphere is associated with speech and symbol manipulation, whereas the right hemisphere processes images and responds to sensory experiences and non-verbal clues.

Herrmann augmented Sperry's left- and right-brain metaphor to incorporate the part that emotions play in thinking. Emotions sway intellect, and intellect tempers emotions $s^{5}$. The resulting 'whole brain' model categorizes thinking styles in four quadrants (see go.nature.com/jfbqky). Left-brain thinking includes rational and safekeeping processes; right-brain thinking includes feeling and creative processes. Of course, human thought is much messier, but this approximation is helpful for understanding communication and conflicts among people.

For example, a professor can use such knowledge to 'up the game' of her research group. She realizes the advantages of matching a student's role in a project to his thinking preferences rather than to her own. Suppose that a laboratory experiment requires detailed accounting and focused individual work. A student with strong safekeeping preferences is likely to be happier and more productive in this role than a student whose preferences incline them towards interpersonal relationships. When matched to their thinking preferences, students are more likely to be motivated, to work happily and efficiently, and to self-manage, leaving more time for the professor to focus on her other priorities.

\section{TEAM SCIENCE}

Research teams are best formed from a mix of diverse thinkers. Most real-world tasks require contributions from all four quadrants. When too many people on a team exhibit the same preference patterns, they tend to compete for the same 'desirable' roles, and it can be hard to find someone to do the 'undesirable' chores. A diverse team gives everyone a chance to contribute in a complementary fashion. And research shows $^{6}$ that gender-balanced teams of diverse thinkers tend to outperform samethinking teams.

Professors tend to be sceptical about many things, and leadership is no exception. Over the years, we have heard many academic colleagues in engineering and science, especially senior ones, express opinions as to why soft skills are pseudoscience and should not be taken seriously: "people skills cannot be measured and understood the way that a subatomic particle, a strand of DNA or a computer algorithm can be"; "humans are unpredictable and emotional and cannot be understood systematically"; and "people skills are unimportant in the academic world because everyone tends to act rationally". It is no wonder that so few universities have bothered to teach leadership skills to their faculty.

Although persuading professors to change is notoriously hard ${ }^{7}$, there are indications that things are improving. Team science $^{8}$ is a rapidly growing cross-disciplinary field of study that aims to maximize the efficiency and effectiveness of team-based research in the sciences. The growing interest in entrepreneurship among technical academics has led to a greater understanding in universities of the importance of leadership skills. And 'big science' endeavours highlight the importance of getting many people to work together effectively. Examples include CERN (Europe's particle-physics lab near Geneva, Switzerland), ENCODE and the many '-ome' projects (such as the Human Genome Project).

But leadership training alone is not enough. Academia must support and reward leadership, embracing the modern understanding that thinking - the cornerstone of academic accomplishment - involves emotion. Engineering and science must adapt to value the quality of interpersonal relationships, which are essential to teamwork. They must respect diversity of thought, especially non-technical modes, if they wish to inspire creativity.

Smooth-functioning and innovative research teams are essential for producing the inventions and discoveries needed to address the many challenging problems that our society faces. .

Charles E. Leiserson is professor of computer science and engineering at the MIT Computer Science and Artificial Intelligence Laboratory, Massachusetts Institute of Technology, Cambridge, Massachusetts, USA. Chuck McVinney is president of McVinney \& Co., a management-consulting firm specializing in facilitating creative thinking and leadership, in Brookline, Massachusetts, USA. e-mails:cel@mit.edu; chuckmcvinney@gmail.com

1. Stephan, P. E. \& Ehrenberg, R. G. Science and the University (Univ. Wisconsin Press, 2007).

2. Kahneman, D. Thinking, Fast and Slow (Farrar, Straus and Giroux, 2011).

3. Herrmann, N. \& Herrmann-Nehdi, A. The Whole Brain Business Book 2nd edn (McGraw Hill, 2015).

4. Gazzaniga, M. S. Tales from Both Sides of the Brain (HarperCollins, 2015)

5. Goleman, D. Emotional Intelligence (Bantam Dell, 1995).

6. DeRidder, C. G. \& Wilcox, M. A. How to Improve Productivity: Whole Brain Teams Set New Benchmarks (Herrmann International, 2006)

7. Bruns, J. W. \& Bruns, D. L. J. Leadersh. Stud. 1, 53-63 (2007).

8. Bennett, L. M., Gadlin, H. \& Levine-Finley, S. Collaboration \& Team Science: A Field Guide (National Institutes of Health, 2010).

The authors declare competing financial interests: see go.nature.com/nlpne9. 